\title{
可见光直接促进的过渡金属催化交叉偶联反应研究进展
}

\author{
李祯龙 $^{a}$ 金 健 $*, b \quad$ 黄莎华 $*, a, b$ \\ $\left({ }^{a}\right.$ 上海应用技术大学化学与环境工程学院 上海 201418) \\ ${ }^{b}$ 中国科学院上海有机化学研究所 中国科学院天然产物有机合成化学重点实验室 \\ 分子合成卓越创新中心 上海 200032)
}

\begin{abstract}
摘要 经过几十年的发展, 过渡金属催化的交叉偶联反应已经成为一类功能强大的有机合成方法, 广泛应用于各种碳 碳键和碳杂原子键的高效构建. 最近几年化学家们发现在越来越多的情况下, 不用外加光敏剂, 可见光能直接促进过 渡金属催化的交叉偶联反应，使原来无法发生或缓慢进行的偶联反应得以顺利实现. 该类反应因条件简单、反应温和 以及无需外加光敏剂等优点受到了广泛的关注. 根据过渡金属的分类，综述了近些年来该类反应的研究进展.
\end{abstract}

关键词＼cjkstart可见光促进; 过渡金属催化; 交叉偶联

\section{Recent Advances in Transition Metal-Catalyzed Cross-Coupling Reactions Directly Promoted by Visible Light}

\author{
Li, Zhenlong ${ }^{a} \quad$ Jin, Jian ${ }^{*, b} \quad$ Huang, Shahua ${ }^{*, a, b}$
}

$\left({ }^{a}\right.$ School of Chemical and Environmental Engineering, Shanghai Institute of Technology, Shanghai 201418)

$\left({ }^{b}\right.$ CAS Key Laboratory of Synthetic Chemistry of Natural Substances, Center for Excellence in Molecular Synthesis, Shanghai Institute of Organic Chemistry, Chinese Academy of Sciences, Shanghai 200032)

\begin{abstract}
Over the last decades, the transition metal-catalyzed cross-coupling reactions have become powerful organic synthetic methods for forming carbon-carbon and carbon-heteroatom bonds. Very recently, the introduction of visible light into transition metal catalysis opened a new avenue for achieving novel, highly enabling cross-coupling reactions that otherwise were elusive. This type of reaction has received extensive attention due to its simple, mild conditions and no need of photocatalyst. Based on the classification of transition metals, the research progress of transition metal-catalyzed cross-coupling reactions directly promoted by visible light is reviewed.
\end{abstract}

Keywords visible light-promoted; transition metal-catalyzed; cross-coupling

过渡金属催化的交叉偶联反应是形成碳碳键和碳 杂原子键非常重要的方法, 在医药、农药和有机高分子 材料等领域得到了广泛的应用 ${ }^{[1]}$. 为了表彰 Heck, Negishi 和 Suzuki 三人在钯催化交叉偶联反应方面做出 的贡献, 在 2010 年他们同时被授予诺贝尔化学奖 ${ }^{[2]}$. 过 渡金属催化交叉偶联反应主要包括 Suzuki-Miyaura, Heck, Sonogashira, Stille, Kumada, Negishi, Ullmann 和 Hiyama 等反应, 通常使用 $\mathrm{Pd}, \mathrm{Au}, \mathrm{Ir}, \mathrm{Ru}, \mathrm{Rh}, \mathrm{Cu}, \mathrm{Ni}, \mathrm{Mn}$, $\mathrm{Co}$ 和 $\mathrm{Fe}$ 过渡金属作为金属催化剂。

光催化技术是一种绿色化学技术, 可以将光能转化
为化学能从而促进化学反应的进行. 可见光促进的有机 化学反应在过去十年获得了广泛的关注和研究, 有力地 推动了光化学反应在工业上的应用. 传统光化学一般采 用能量较高的紫外光来引发反应, 可能会使得反应剧烈 导致反应选择性差、副反应多等问题. 对于大多数有机 化合物而言，温和的可见光并不能直接引发其反应，而 光敏剂的引入使得众多独特、高效的有机转化得以实现. 这类反应通常被称作光氧化还原催化反应，广泛地被认 可的机理是，光敏剂吸收可见光以后到达激发态，然后 与有机底物分子发生单电子转移或能量转移过程, 从而

\footnotetext{
* Corresponding authors. E-mail: jjin@sioc.ac.cn; shahua@sit.edu.cn

Received October 23, 2019; revised November 21, 2019; published online December 11, 2019.

Project supported by the National Natural Science Foundation of China (No. 21402121) and the Collaborative Innovation Program of Shanghai Institute of Technology (No. XTCX2015-16).

国家自然科学基金(No. 21402121)和上海应用技术大学协同创新计划(No. XTCX2015-16)资助项目.
} 
促使有机反应的发生 ${ }^{[3]}$.

近些年来, 光氧化还原催化与过渡金属催化逐渐发 生结合，在可见光照射条件下光敏剂和过渡金属共同催 化偶联反应已经成为有机合成中的一种非常有效的新 策略. 在该类催化体系中, 处于激发态的光敏剂与过渡 金属催化剂或有机底物分子发生单电子转移或能量转 移, 从而促进交叉偶联反应的进行. 但是在常用的光敏 剂中, 金属光敏剂钌 $(\mathrm{Ru}) 、$ 铱 $(\mathrm{Ir})$ 络合物稀缺昂贵, 而有 机光敏剂在稳定性和催化效率方面又稍差些 ${ }^{[4]}$.

最近几年化学家们发现, 在很多情况下不用外加光 敏剂, 可见光能直接促进过渡金属催化的交叉偶联反 应. 在有些情况下, 过渡金属催化剂除了参与偶联步骤 还发挥光敏剂的作用, 可与有机底物分子发生单电子转 移; 还有些情况下, 则是可见光为偶联反应的氧化加成 或还原消除步骤提供能量, 使得原来无法发生或缓慢进 行的偶联反应顺利实现. 这不仅大大提高了交叉偶联反 应的转化效率, 而且极大地扩展了反应类型. 可见光直 接促进过渡金属催化的交叉偶联反应也因反应条件简 单、反应温和以及无需外加光敏剂等优点受到了化学家 的广泛关注. 本文将根据过渡金属的分类，总结了近些 年来可见直接促进过渡金属交叉偶联反应的研究进展.

\section{1 可见光直接促进的铜催化交叉偶联反应}

2012 年, Hwang 课题组 ${ }^{[5]}$ 首次报道了可见光直接促 进的铜催化交叉偶联反应. 该课题组采用 $\mathrm{CuCl}$ 作为催 化剂, 在可见光照射条件下实现了无钯参与的 Sonogashira 交叉偶联反应(Scheme 1). 该反应的底物范围广, 适用于多种碘代和溴代芳烃底物, 取代基的电子效应对 反应几乎没有影响，均能取得良好至优秀的收率. 该反 应的优势在于不需要添加额外的配体, 在常温下就可以 实现. 机理实验研究表明, 苯乙炔在碱的作用下与 $\mathrm{CuCl}$ 原位生成苯乙炔铜复合物 $\mathbf{1}$, 然后该复合物吸收可见光, 使电子从苯乙炔向金属方向迁移(LMCT), 导致苯乙炔 部分缺电子而吸引富电子的芳基靠近, 生成中间体复合 物 2, 该复合物随即发生单键复分解得到偶联产物和 $\mathrm{CuCl}$.

2016 年, Hwang 课题组 ${ }^{[6]}$ 发展了以 $\mathrm{CuCl}$ 作为催化 剂, 可见光促进的富电子/中性芳香炔烃与缺电子芳香 炔烃的交叉偶联反应(Eq. 1). 反应收率中等以上，作者 认为两种炔底物先配位到铜上, 选择性地形成稳定的基 态杂二聚乙炔铜复合物 $\mathbf{3}$, 然后在光照作用下通过分子 内配体一配体偶联生成目标产物. 该反应选择性进行交 叉偶联很可能与杂二聚乙炔铜复合物 $\mathbf{3}$ 的偶极性质(同 时具有富电子和缺电子部分)有关, 因为极性有机溶剂 有助于稳定复合物 3 , 而不能很好地稳定均二聚乙炔铜
复合物.

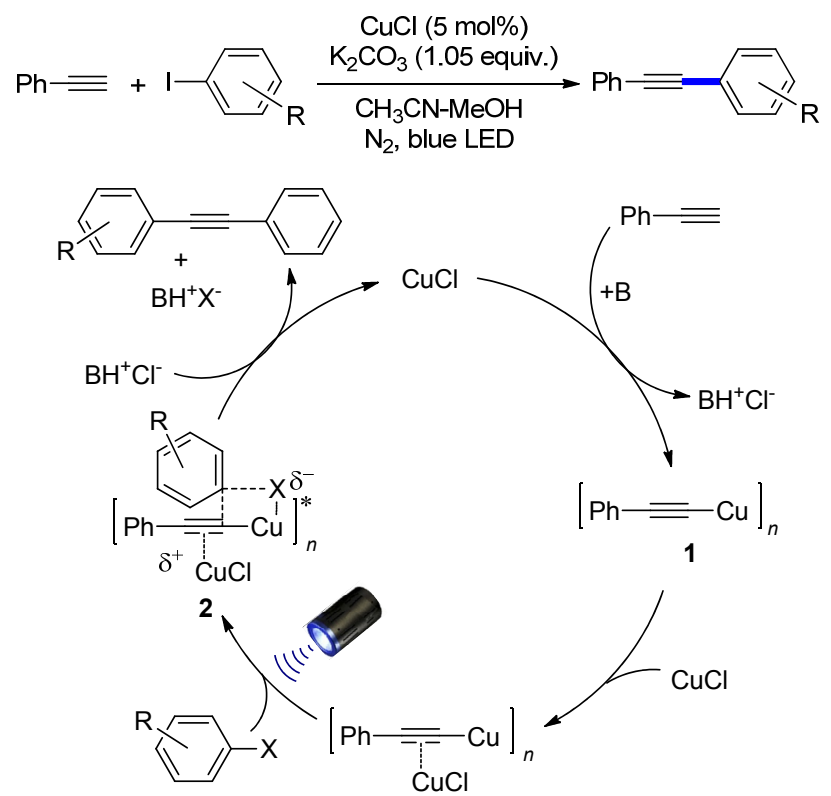

图式 1 可见光直接促进的铜催化苯乙炔和碘苯的交叉偶联 反应

Scheme 1 Copper-catalyzed cross-coupling reaction of phenylacetylene and iodobenzene directly promoted by visible light

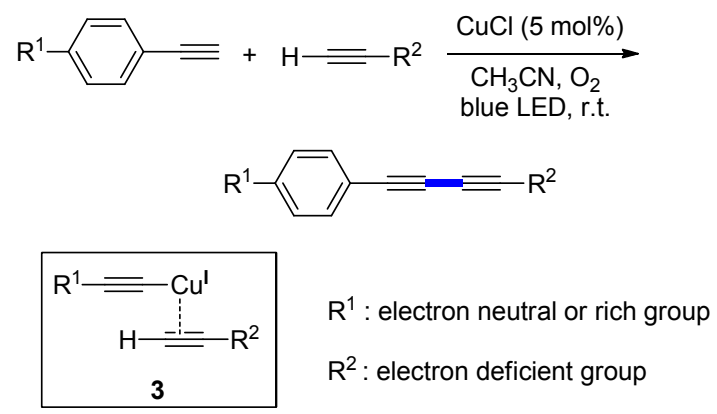

2018 年, Hwang 课题组 ${ }^{[7]}$ 报道了可见光促进的铜催 化肼基吡啶与末端炔烃的脱氮氧化偶联反应(Eq. 2). 该 反应以 $\mathrm{CuCl}$ 作为催化剂, $\mathrm{O}_{2}$ 作氧化剂, 在可见光照射下 生成偶联产物, 副产物仅为 $\mathrm{N}_{2}$ 和 $\mathrm{H}_{2} \mathrm{O}$. 反应简单绿色高 效, 这也是在室温下有关 $\mathrm{N}_{2}$ 消除(非活化 $\mathrm{C}-\mathrm{N}$ 键裂解) 的首次报道.

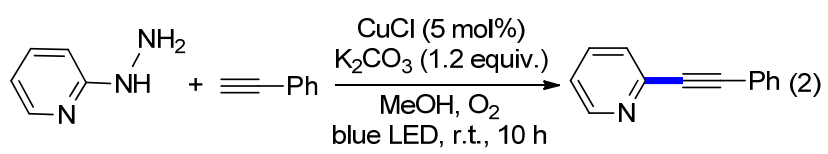

2012 年, $\mathrm{Fu}$ 和 Peters 等 ${ }^{[8]}$ 报道了紫外光促进的铜催 化咔唑与芳基/烷基卤化物的 Ullmann $\mathrm{C}-\mathrm{N}$ 交叉偶联反 应. 研究表明该反应的关键是原位生成的咔唑复合物在 紫外光照射条件下可与芳基/烷基卤化物之间发生单电 子转移, 生成芳基/烷基自由基. 随后, 他们相继报道了 光促进铜催化的多种交叉偶联反应，包括 $\mathrm{C}-\mathrm{S} 、 \mathrm{C}-\mathrm{O}$ 
和 $\mathrm{C}-\mathrm{C}$ 键形成反应 ${ }^{[9]} .2016$ 年, $\mathrm{Fu}$ 和 Peters 等 ${ }^{[10]}$ 首次报 道了可见光直接促进的铜催化不对称 $\mathrm{C}-\mathrm{N}$ 交叉偶联反 应(Scheme 2). 在 $(S)-\mathbf{L} 1 *$ 手性配体作用下, 以咔唑与外 消旋的三级烷基氯化物反应，生成单一对映体的产物， 该反应收率在 $73 \%$ 以上, ee 值最高达 $99 \%$. 铜参与了光 化学和对映选择性成键两个步骤. 铜、手性配体和咔唑 亲核试剂原位生成具有光氧化还原活性的铜复合物是 该反应的关键.

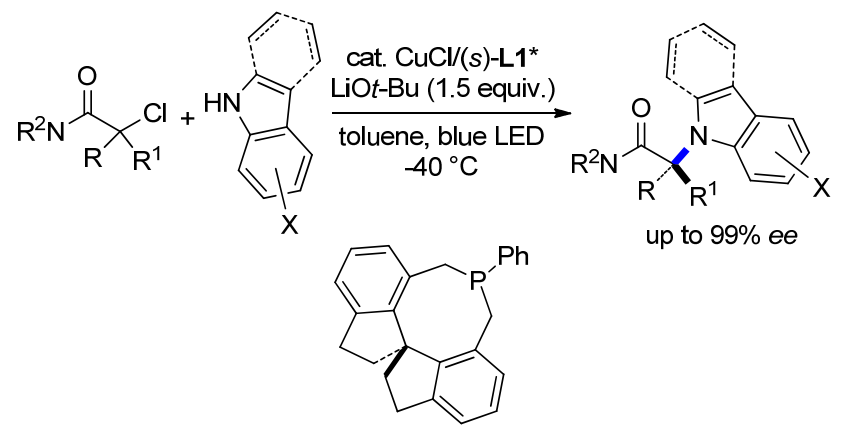

(S)-L1*
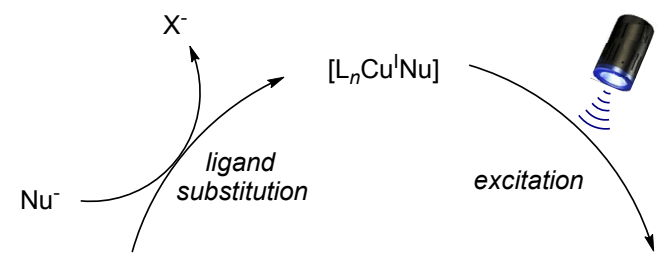

$\left[\mathrm{L}_{n} \mathrm{Cu}{ }^{\mathrm{X} X}\right]$

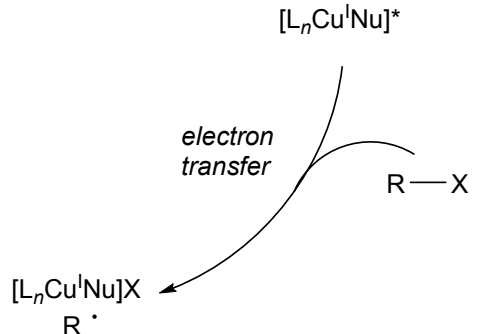

$R^{\cdot}$

图式 2 可见光直接促进的铜催化咔唑和三级烷烃卤代物的 不对称交叉偶联反应

Scheme 2 Copper-catalyzed asymmetrically cross-coupling reaction of carbazole and tertiary alkane halides directly promoted by visible light

2017 年, $\mathrm{Fu}$ 和 Peters 等 ${ }^{[11]}$ 发展了可见光促进的铜催 化脱羧 $\mathrm{C}-\mathrm{N}$ 偶联反应 $(\mathrm{Eq} .3)$. 反应收率中等以上, 底 物适用范围广, 对一些复杂底物同样适用, 而且该反应 可作为 Curtius 重排的替代方法, 避免了 Curtius 重排需 要处理叠氮化合物所面临的安全问题. 机理研究表明铜 在光化学和偶联反应上都起了关键作用.

同年, $\mathrm{Fu}$ 和 Peters 等 ${ }^{[12]}$ 应用类似策略在可见光和铜 的共同催化下实现了脂肪胺和二级烷基碘化物的 $\mathrm{C}-\mathrm{N}$ 偶联反应(Eq. 4). 反应以中等以上的收率生成目标产物, 该反应优势在于能够克服传统 $\mathrm{S}_{\mathrm{N}} 2$ 反应的不足(在 $\mathrm{S}_{\mathrm{N}} 2$ 反应中容易出现 $\mathrm{E}_{2}$ 反应和双取代反应), 也能克服空间
位阻对反应的影响.
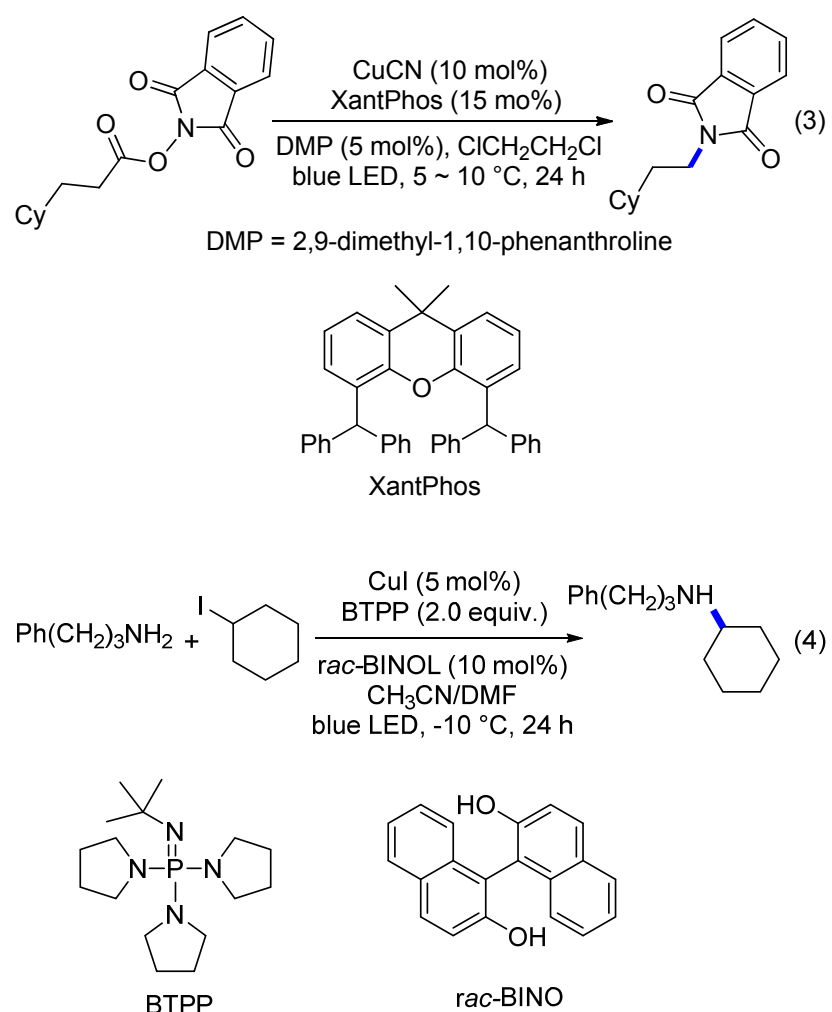

随后，该课题组 ${ }^{[13]}$ 还设计、合成了咔唑一双膦新型 三齿配体 L2, 并应用于可见光促进的 Ullmann C- $\mathrm{N}$ 偶 联反应，在室温下实现一系列伯氨基甲酸酯与非活化烷 基溴的交叉偶联(Eq. 5). 在该反应中铜盐不仅能做金属 偶联试剂, 而且还能和咔唑一双膦新型三齿配体 L2 生成 铜复合物 4 , 该复合物在光照下具有光氧化还原催化剂 的作用.<smiles>[R]OC(=O)NC([R])[R17]([H])([H])[H]</smiles>

2018 年, 该课题组 ${ }^{[14]}$ 又报道了可见光促进的铜催 化卤代烷烃、烯烃和三氟甲基硫醇盐的三组分偶联反应， 得到三氟甲基硫醚化合物(Eq. 6). 作者认为 $\mathrm{Cu}(\mathrm{I})$ 、配体 和 $\mathrm{SCF}_{3}$ 络合生成的 $\mathrm{Cu}(\mathrm{I})$ 复合物充当还原剂, 在光照作 用下将一个电子传递给亲电试剂从而生成烷基自由基, 该自由基又与烯烃和 $\mathrm{Cu}(\mathrm{II})$ 复合物串联反应得到偶联产 物. 作者还用该方法尝试合成了溴代产物 5、氰基化产 
物 6 和叠氮产物 7.

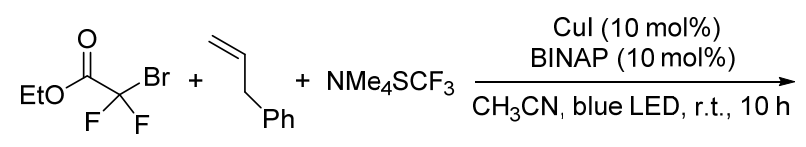<smiles>CCOC(=O)C(F)(F)CC(Cc1ccccc1)C(F)(F)F</smiles><smiles>c1ccc(P(c2ccccc2)c2ccc3ccccc3c2-c2c(P(c3ccccc3)c3ccccc3)ccc3ccccc23)cc1</smiles>

BINAP<smiles>CCOC(=O)C(F)(F)CC(C#N)c1ccccc1</smiles>

$6 \mathrm{Ph}$<smiles>CCOC(=O)C(F)(F)CC(Br)Cc1ccccc1</smiles>

5<smiles>NC(CCC(F)(F)F)c1ccc(-c2ccccc2)cc1</smiles>

同年, Lalic 课题组 ${ }^{[15]}$ 报道了室温下可见光促进的铜 催化烷基碘代物 Sonogashira 偶联反应(Eq. 7). 该反应适 用于各级碘代物，收率最高可达 $99 \%$ ，并且兼容酯、氯、 醇、酰胺、环氧化物、卤代芳烃和醚等官能团. 作者发 现在不加配体情况下, 该反应会生成大量的炔烃聚合 物, 而三叔丁基三联吡啶配体 $\mathbf{L 3}$ 可以调节激发态炔铜 复合物 8 的反应性, 抑制聚合物的生成. 作者认为该反 应机理可能与激发态炔铜复合物对烷基碘代物的单电 子转移以及烷基自由基的产生有关.<smiles>C#CC(C)CC(C)=O</smiles>

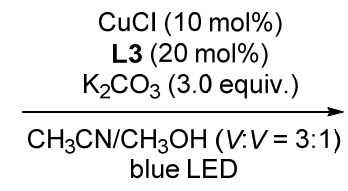<smiles>CC(C)(C)c1ccnc(-c2cc(C(C)(C)C)cc(-c3cc(C(C)(C)C)ccn3)n2)c1</smiles>

L3<smiles>CCCCC#CC(C)OC</smiles>

8
随后, 肖文精课题组 ${ }^{[16]}$ 报道了可见光促进的铜催 化肟酸酯、苯乙烯和硼酸的三组分交叉偶联反应(Eq. 8). 首先肜酸酯被铜催化剂还原生成亚胺基自由基，随后四 元环的碳碳键发生裂解生成氰基烷基自由基. 该自由基 加成到苯乙烯末端形成苄基自由基, 然后与芳基硼酸转
金属化形成的 $\mathrm{ArCu}^{\mathrm{II}}$ 复合物结合，经还原消除得到含 1,1-二芳基甲烷的烷基腈. 该反应首次使用氰基烷基自 由基和烯烃加成生成的自由基来作为烷基卤代物的一 种替代物，与苯硼酸进行交叉偶联反应.

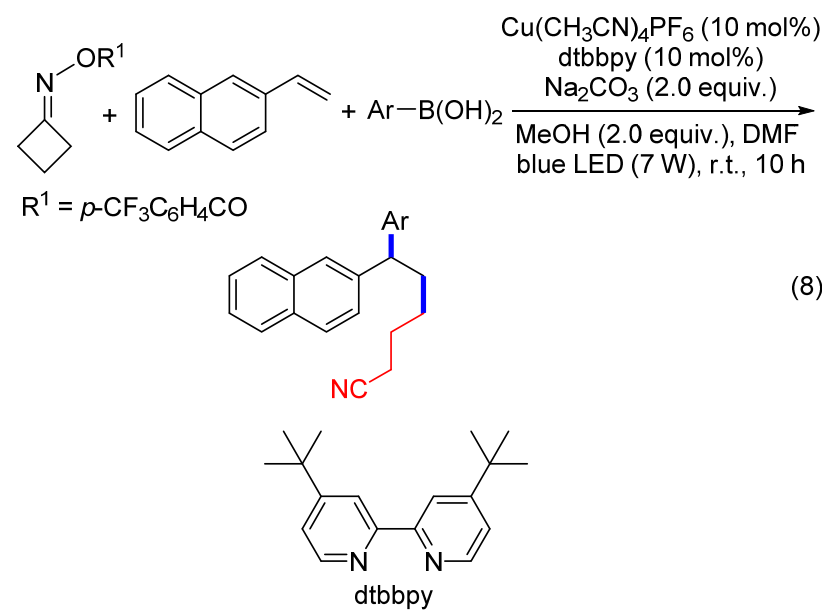

2019 年, 郭丽娜课题组 ${ }^{[17]}$ 也报道了在可见光条件 下铜催化的肟酸酯和胺的偶联反应(Eq. 9), 该反应底物 适用范围非常广，可适用于(杂)芳胺、芳香氮杂环、磺 酰胺和烷基胺等各种含氮亲核试剂.

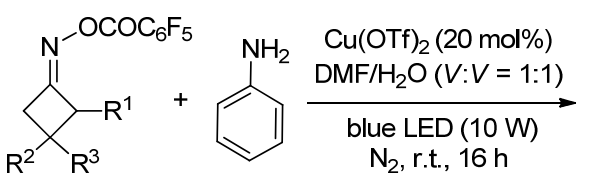<smiles>[R]C(Nc1ccccc1)C([R])([R])CC#N</smiles>

最近, 张国柱课题组 ${ }^{[18]}$ 报道了可见光促进的铜催 化氟烷基卤化物、烯烃和胺的三组分偶联反应(Eq. 10), 从而获得了有价值的含氟烷基胺化合物. 在该反应中 $\mathrm{CuCl}$ 具有双重作用, 可与胺类底物形成具有可见光吸 收特性的铜复合物以及作为金属催化剂参与偶联反应.

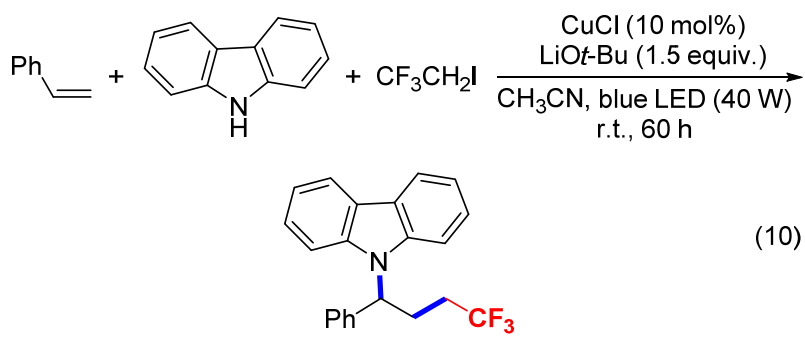

\section{2 可见光直接促进的镍催化交叉偶联反应}

近些年来, 在可见光照射条件下光敏剂和镍共同催 化的交叉偶联反应有了飞速的发展, MacMillan、Molander 和 Doyle 等课题组在该领域报道了大量可见光促进 的交叉偶联反应新方法 ${ }^{[4,19]}$. 除此之外, 可见光直接促 
进镍催化的交叉偶联反应也相继被报道.

2018 年, Alcázar 课题组 ${ }^{[20]}$ 报道了在不加外源光敏 剂的情况下, 可见光促进的镍催化 Negishi 交叉偶联反 应(Scheme 3). 作者在有光和没光的条件下分别对反应 进行了考察, 有光条件下的产率要远远高于无光条件下 的产率，甚至有些底物在无光条件下不反应. 值得一提 的是, 该反应底物范围广, 不仅适用于溴代芳烃, 对氯 代芳烃也同样适用. 通过紫外-可见光吸收实验, 作者 提出可见光在 $\mathrm{Ni}^{\mathrm{II}}$ 还原成 $\mathrm{Ni}^{0}$ 和还原消除偶联两方面都 有促进作用. 随后, 该课题组 ${ }^{[21]}$ 研制了针对该类反应的 放大设备, 该设备集流体、光化学、固体试剂的使用和 NMR 在线检测为一体, 能以克级规模实现该偶联反应, 生产效率范围在 3.4 $5.6(\mathrm{~g} / \mathrm{h})$.

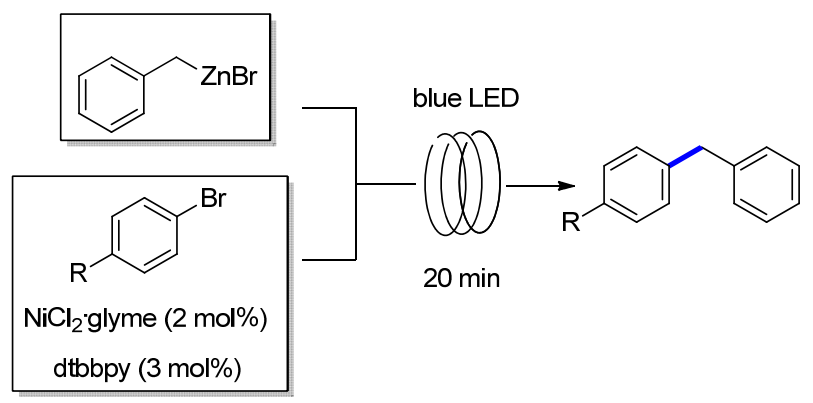

图式 3 可见光直接促进的镍催化锌格氏试剂与溴苯交叉偶 联反应

Scheme 3 Nickel-catalyzed cross-coupling reaction of zinc Grignard reagent with bromobenzene directly promoted by visible light

最近, Melchiorre 课题组 ${ }^{[22]}$ 报道了可见光介导的镍 催化的不对称酰基交叉偶联反应(Eq. 11). 该反应在手 性配体 L4 作用下, 以对称酸酐和 4-烷基二氢吡啶(DHP) 化合物为底物, 成功地得到了对映体富集的 $\alpha$-取代的酮 化合物, $e e$ 值最高达 $95 \%$. 4-烷基二氢吡啶化合物在反应 中可同时作为自由基源和还原剂是该反应的关键. 在可 见光照射下, 4-烷基二氢吡啶化合物先被活化成激发态, 随后经单电子转移, 将 $\mathrm{Ni}^{\mathrm{I}}$ 还原成 $\mathrm{Ni}^{0}$ 并生成 4-烷基二氢 吡啶的正离子自由基中间体. 该中间体不稳定, 分解得 到相应自由基，随后该自由基参与镍介导的偶联反应

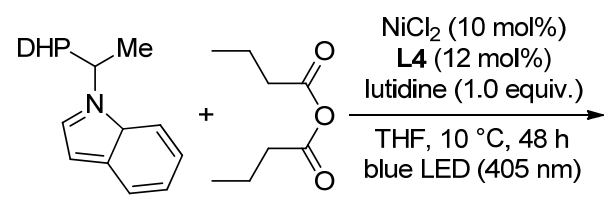<smiles>CCOC(=O)C1=C(C)NC(C)=C(C(=O)OCC)C1C</smiles>

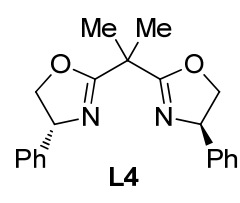

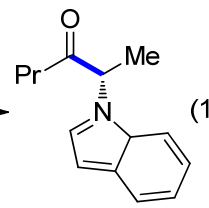

up to $95 \%$ ee
得到目标产物.

\section{3 可见光直接促进的钴催化交叉偶联反应}

由于钴廉价、稳定且具有较高的催化活性, 用钴催 化剂实现交叉偶联反应也是化学家关注的焦点 ${ }^{[23]}$. 2011 年, Carreira 课题组 ${ }^{[24]}$ 基于 $\mathrm{Co}^{\mathrm{III}}-\mathrm{H}$ 在碱性条件下可以去 质子化生成 $\mathrm{Co}^{\mathrm{I}}$ 的特点, 在可见光照射下实现了第一例 钴催化烷基碘和烯烃的分子内 Heck 型偶联反应 (Scheme 4). 该反应首先生成烷基 $\mathrm{Co}^{\mathrm{III}}$ 中间体, 对烯烃 进行插入反应, 随后发生 $\beta$-H 消除, 得到烯基化的产物.
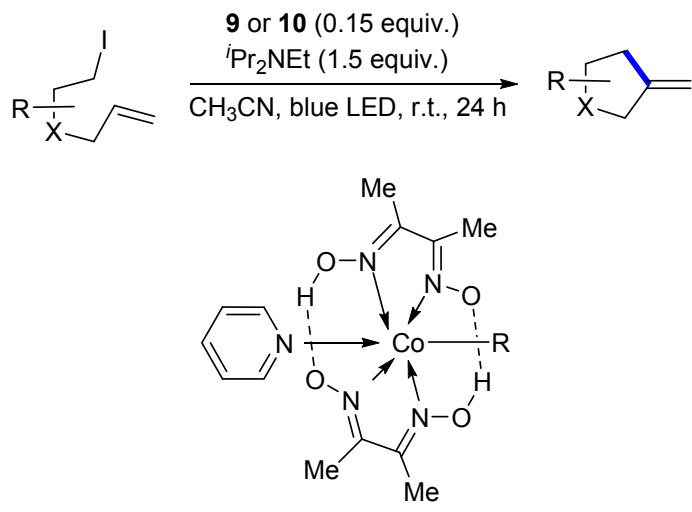

9: $\mathrm{R}=\mathrm{SnPh}_{3}$ 10: $\mathrm{R}={ }^{i} \mathrm{Pr}$

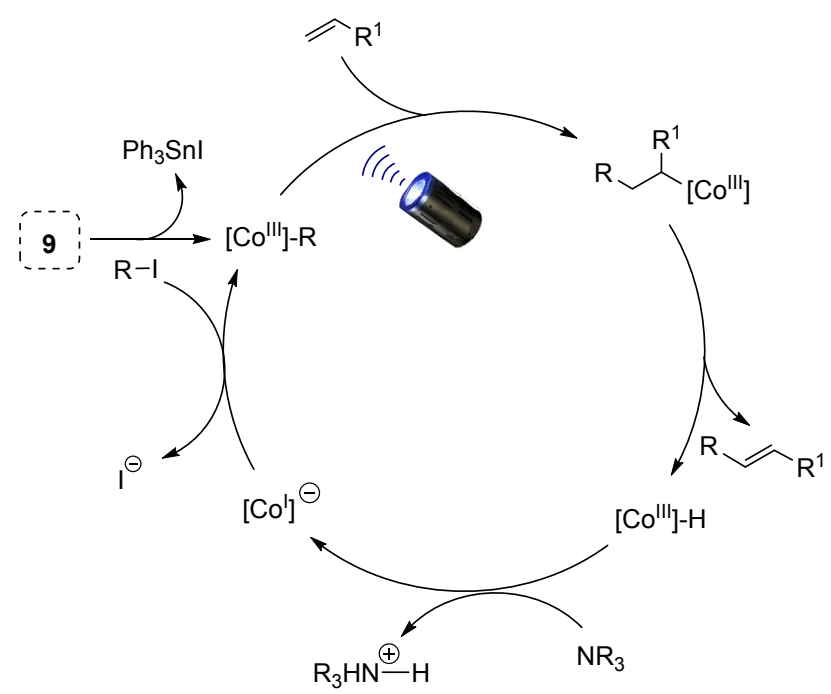

图式 4 可见光直接促进的钴催化的烷基碘和烯烃的分子内 交叉偶联反应

Scheme 4 Cobalt-catalyzed intramolecular cross-coupling of alkyl iodide and olefin directly promoted by visible light

2013 年, Martin 和 Carreira 等 ${ }^{[25]}$ 接着报道了可见光 促进的钴催化烷基碘和烯烃的分子间 Heck 型反应(Eq. 12). 该反应以苯乙烯和三氟乙基碘为底物合成了许多 烯丙基三氟甲烷产物. 然而, 脂肪族烯烃与该体系不相 容，该体系仅适用于具有不同官能团的苯乙烯. 


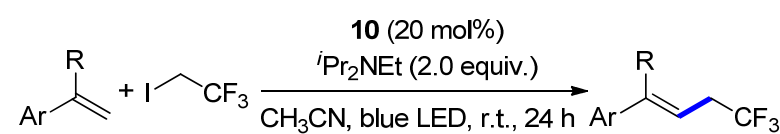

2017 年, 初文毅课题组 ${ }^{[26]}$ 在室温下用乙醇作溶剂, 将 $\mathrm{Co}(\mathrm{OAc})_{2} \cdot 4 \mathrm{H}_{2} \mathrm{O}$ 与过量的 2-(差基亚氨基)-1-苯基丙 烷-1-酮反应得到复合物 11, 随后, 该课题组将其作为催 化剂在可见光条件下实现了 Sonogashira 交叉偶联反应. 作者用溴苯化合物和末端炔烃反应生成相应的苯乙炔 化合物, 产率中等以上. 作者提出了可能的机理: 首先 $\mathrm{Co}^{\mathrm{II}}$ 复合物 11 经还原生成 $\mathrm{Co}^{\mathrm{I}}$ 复合物 12 , 随后与溴苯氧 化加成生成 $\mathrm{Co}^{\mathrm{III}}$ 复合物 13 ; 在光照条件下 $\mathrm{Co}^{\mathrm{III}}-\mathrm{R}$ 键均 裂生成 $\mathrm{Co}^{\mathrm{II}}$ 复合物 14 和苯自由基, 苯自由基与苯乙炔加 成得到的烯基自由基与 $\mathrm{Co}^{\mathrm{II}}$ 复合物 14 结合, 生成 $\mathrm{Co}^{\mathrm{III}}$ 复合物 15, 最后在碱的作用下消除生成偶联产物 (Scheme 5).

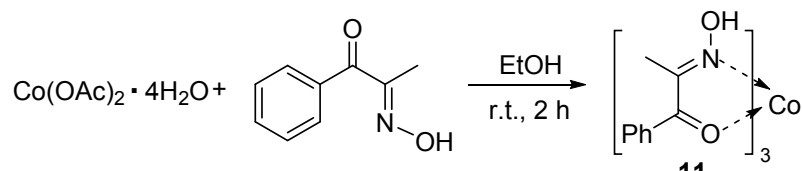

11

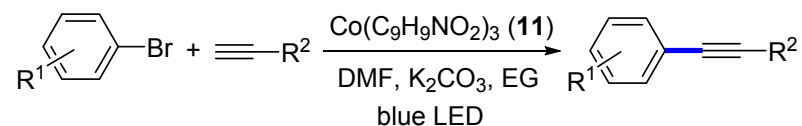

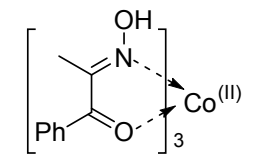

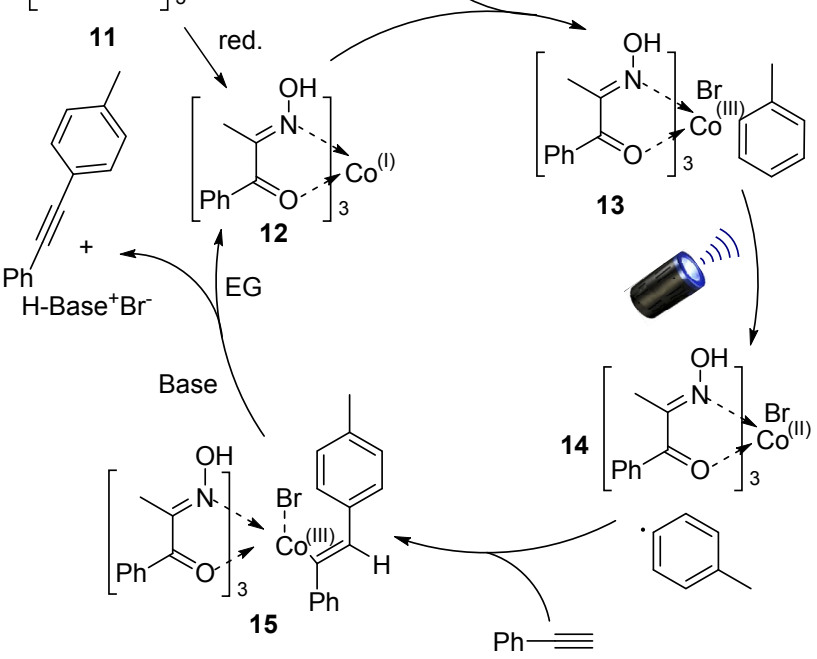

图式 5 可见光直接促进的钴催化的溴苯和末端炔烃交叉偶 联反应

Scheme 5 Cobalt-catalyzed cross-coupling reaction of bromobenzene and terminal alkynes directly promoted by visible light

最近, Rovis 课题组 ${ }^{[27]}$ 报道了可见光促进钴催化的 $[2+2+2]$ 环加成反应(Scheme 6). 作者以苯乙炔和烷基 二炔类化合物为底物, 分别在有光敏剂和无光敏剂条件 下做了对照实验. 在不添加光敏剂情况下, 该反应也能
顺利进行. 机理实验表明苯乙炔首先和 $\mathrm{Co}^{\mathrm{II}}$ 经亚乙烯中 间体生成苯乙炔钴化合物，随后二炔化合物作为双齿配 体与苯乙炔钴化合物加成得到复合物 16, 该复合物在 可见光照射下经配体到金属单电子转移(LMCT)过程生 成芳基碳正离子自由基复合物 17. 该复合物经氧化关 环得到复合物 18, 复合物 18 进一步被还原，随后经苯 炔插入和还原消除得到偶联产物.
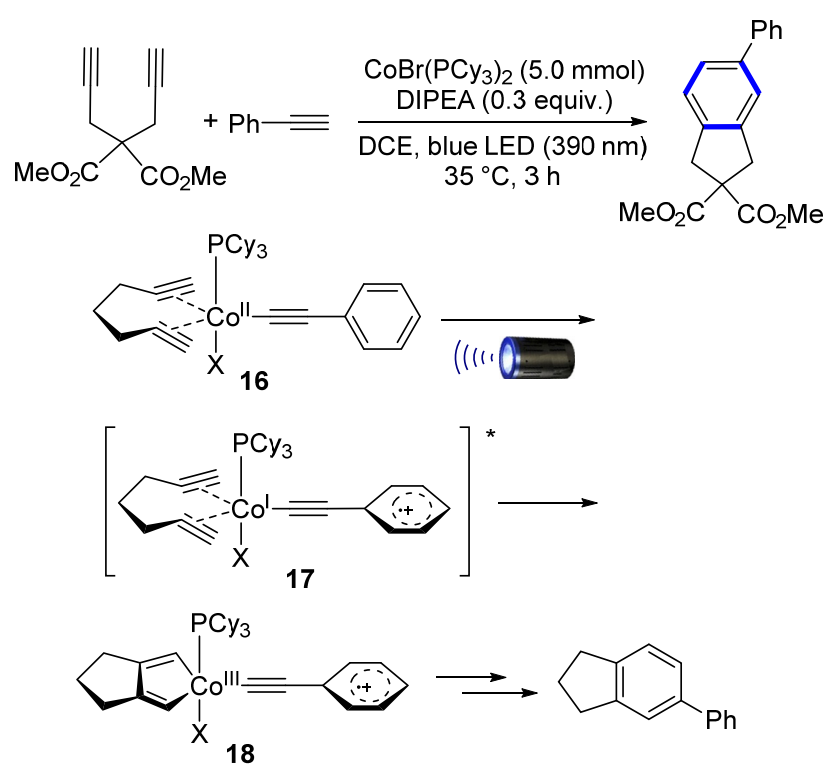

图式 6 可见光直接促进的钴催化的二炔和苯乙炔交叉偶联 反应

Scheme 6 Cobalt-catalyzed cross-coupling reaction of diyne and phenylacetylene directly promoted by visible light

\section{4 可见光直接促进的铁催化交叉偶联反应}

铁作为金属偶联试剂在偶联反应中扮演者非常重 要的角色 ${ }^{[28]}$. 探索用含量丰富且价格低廉的金属铁作 为金属催化剂, 在可见光条件下直接催化交叉偶联反应 具有非常重大的意义.

最近, Alcázar 和 Noël 等 ${ }^{[29]}$ 报道了可见光促进的铁 催化 $\mathrm{C}\left(\mathrm{sp}^{2}\right)-\mathrm{C}\left(\mathrm{sp}^{3}\right)$ 的 Kumada 偶联反应(Scheme 7). 该 反应在流动装置中进行，收率中等以上. 值得一提的是， 该反应也适用于富电子的非活化芳基氯代物，在底物范 围上有很大的突破. 作者通过紫外-可见光吸收光谱分 析和密度泛函理论计算，发现该反应会产生 $\mathrm{Fe}^{\mathrm{I}}$ 物种， 并且在光照条件下 $\mathrm{Fe}^{\mathrm{III}}$ 会增加. 因此作者提出格氏试剂 先将 $\mathrm{Fe}^{\mathrm{III}} 19$ 还原成 $\mathrm{Fe}^{\mathrm{I}} \mathbf{2 0}$, 而可见光的照射促进了 $\mathrm{Fe}^{\mathrm{I}}$ 20 与芳基氯代物的氧化加成.

\section{5 可见光直接促进的钯催化交叉偶联反应}

由于钯具有非常好的催化活性，钯催化交叉偶联反 应一直是研究的热门与重点 ${ }^{[2,30]}$. 近三年来, 可见光直 


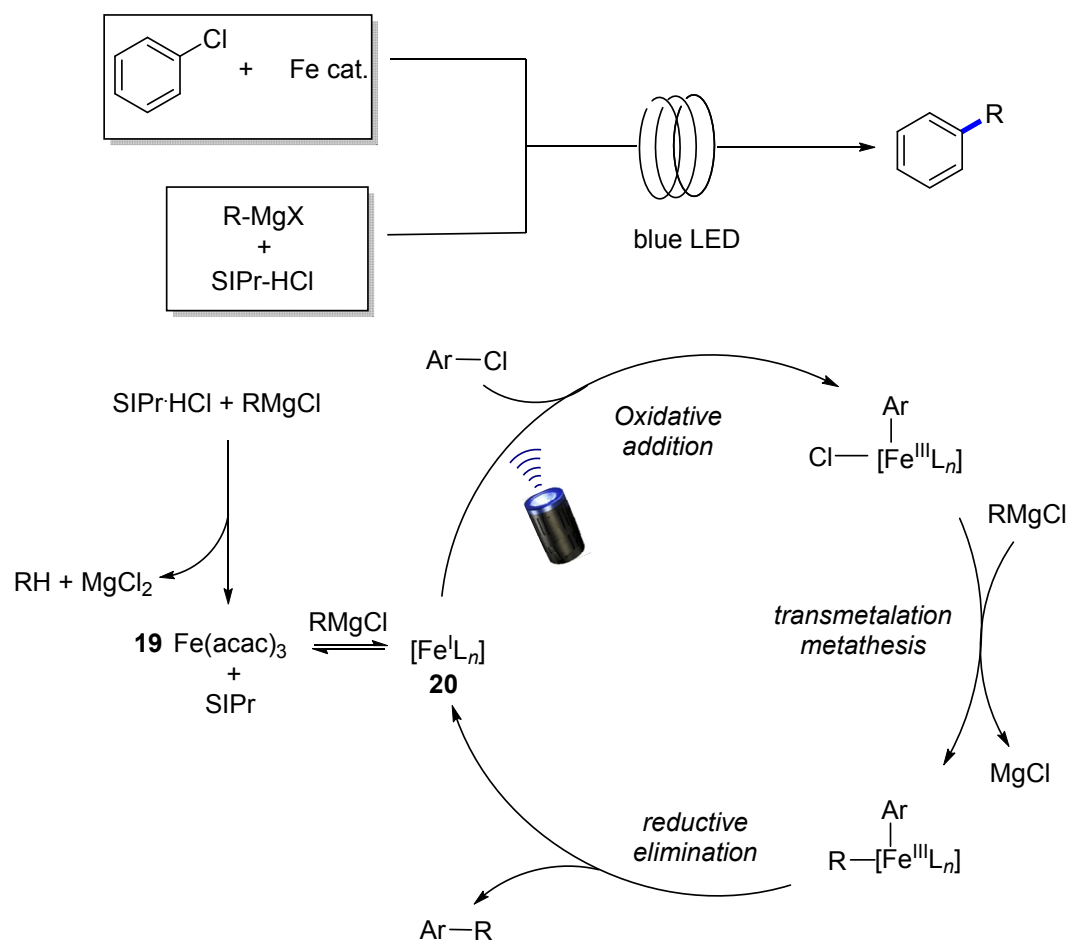

图式 7 可见光直接促进的铁催化的芳基氯代物和格氏试剂交叉偶联反应

Scheme 7 Iron-catalyzed cross-coupling reaction of Grignard reagent and aryl chloride directly promoted by visible light

接促进钯催化的交叉偶联反应的有了快速发展, 化学家 们已经开发出了一系列新型的 Suzuki-Miyaura、Heck 和 Negishi 等偶联反应.

2017 年, Odell 课题组 ${ }^{[31]}$ 报道了可见光直接促进的 钯催化非活化卤代烷烃与芳基硼酸的羰基化 SuzukiMiyaura 偶联反应(Eq. 13), 该反应在双室反应装置中进 行, 产率中等以上. 值得一提的是, 具有挑战性的烷基 溴代物也适用于该反应, 而且该方法用固体 $\mathrm{CO}$ 源 $\left(\mathrm{Mo}(\mathrm{CO})_{5}\right)$ 来替代气态 $\mathrm{CO}$, 不需要使用高压条件, 反应 安全便捷.

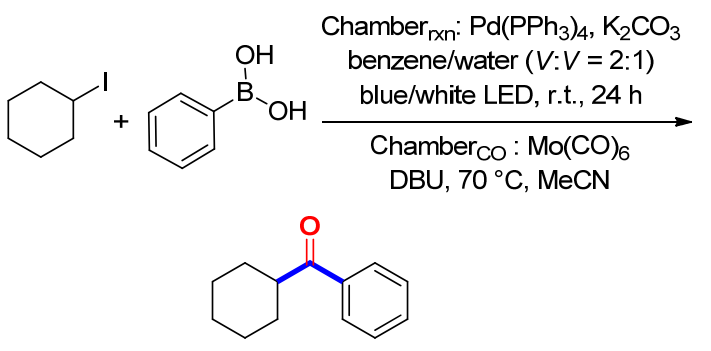

同年, Gevorgyan 课题组 ${ }^{[32]}$ 报道了可见光直接促进 的钯催化卤代烷烃与(杂)芳基乙烯的 Heck 型交叉偶联 反应，合成一系列含烯丙基片段的化合物(Eq. 14). 通过 对照实验作者发现, 纯加热条件无法促使反应发生, 而 且对于非活化的卤代烷烃, 该反应所得到产物具有更高 的 $E / Z$ 立体选择性.

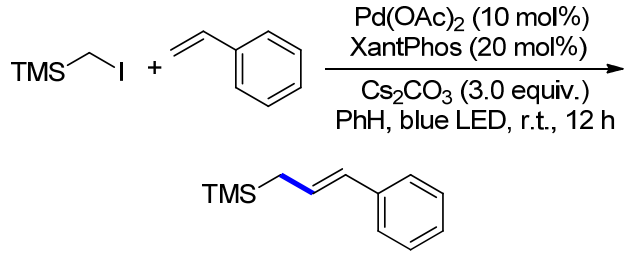

随后，傅尧课题组 ${ }^{[33]}$ 也报道了可见光促进的钯催 化非活化卤代烷烃的 Heck 反应(Eq. 15). 该反应不仅适 用于各级溴代烷烃，还能抑制不必要的 $\beta$ 消除副反应. 作者认为这与激发态的 $\mathrm{Pd}$ 复合物具有自由基和有机金 属双重反应性有关. 值得注意的是，该反应在无光照基 态 Pd 复合物情况下是不能实现的.

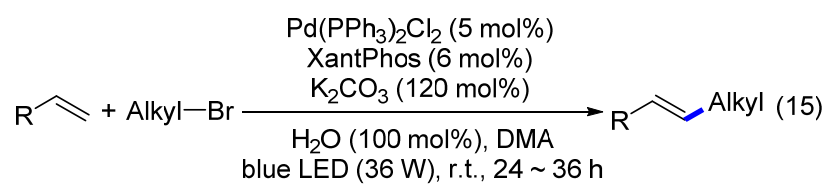

与此同时, 余达刚课题组 ${ }^{[34]}$ 也报道了可见光促进 的钯催化非活化溴代烷烃和烷基胺 $\alpha-\mathrm{C}-\mathrm{H}$ 键的偶联反 应(Eq. 16). 该反应使用各级非活化溴化烷烃，以中等以 上收率选择性生成 $\mathrm{C}\left(\mathrm{sp}^{2}\right)-\mathrm{C}\left(\mathrm{sp}^{3}\right)$ 键.

2018 年, Gevorgyan 课题组 ${ }^{[35]}$ 报道了碘代烷烃的 Heck 反应. 该反应对不同电性的烯烃底物都适用. 研究 表明不同类型的底物反应机理存在差异. 电中性和缺电 子的烯烃可能是通过 Pd 杂化自由基机理(21-22-23), 富 


$$
\begin{aligned}
& \underset{\mathrm{H}}{\stackrel{\mathrm{Pd}\left(\mathrm{PPh}_{3}\right)_{4}(6 \mathrm{~mol} \%)}{2,4,6 \text {-collidine }(2.0 \text { equiv. })}} \\
& \overbrace{\mathrm{Bu}^{t}}^{\mathrm{Nh}}
\end{aligned}
$$

电子的烯烃可能通过杂化自由基/阳离子途径(21-22-

24-25)进行(Scheme 8).
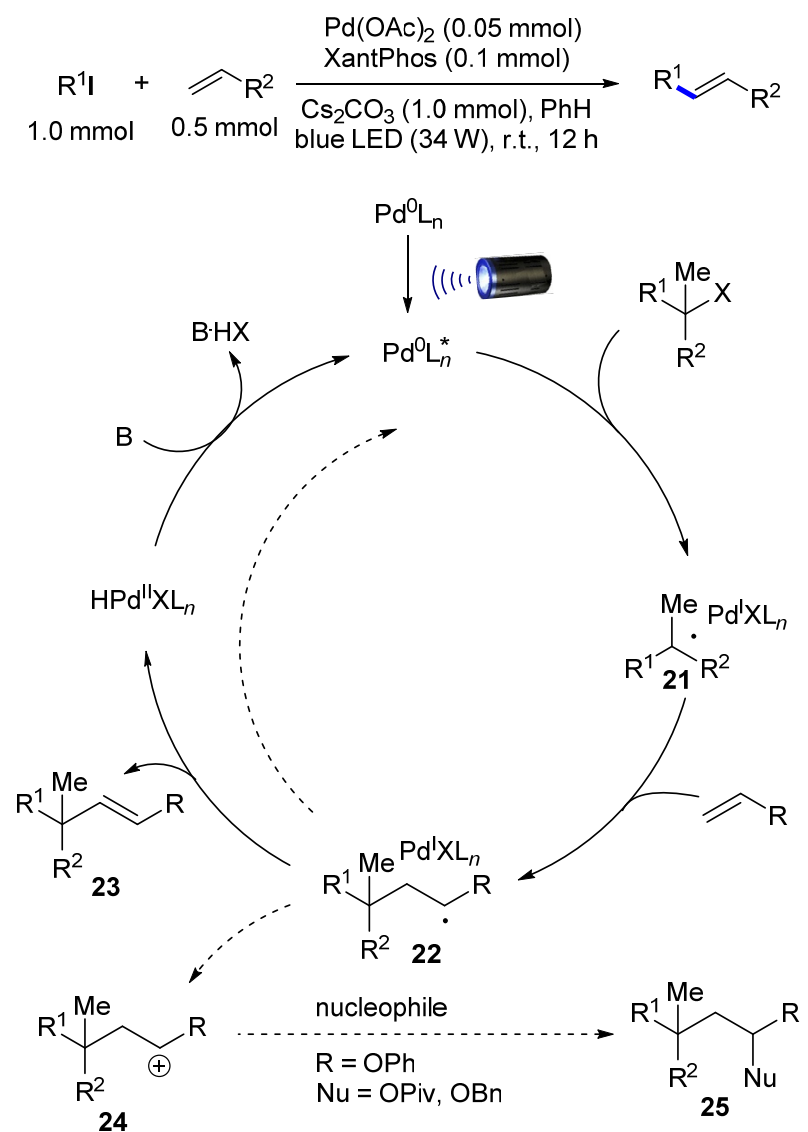

图式 8 可见光直接促进的钯催化碘代烷烃和烯烃交叉偶联 反应

Scheme 8 Palladium-catalyzed cross-coupling reaction of iodoalkanes and olefins directly promoted by visible light

同时, 傅尧课题组 ${ }^{[36]}$ 报道了室温下可见光促进的 钯催化活性羧酸酯( $N$-酰氧基邻苯二甲酰亚胺)的 Heck 型交叉偶联反应(Eq. 17). 机理实验表明, 该反应的关键 在于反应过程中会产生烷基钯复合物. 随后, 该课题 组 ${ }^{[37]}$ 利用烷基钯复合物特点, 开发了烷基溴代物与杂 环交叉偶联反应(Eq. 18), 该反应适用于二级三级溴代 烷烃, 收率中等至优秀, 机理研究表明膦配体在氧化加 成步骤中起着重要的作用.

同年, Glorius 课题组 ${ }^{[38]}$ 也报道了类似的 Heck 型偶 联反应(Eq. 19). 该反应不需要额外加入配体和碱, 反应 条件更加简单, 机理实验表明光激发态的钯催化剂与
$\mathrm{N}$-酰氧基邻苯二甲酰亚胺发生单电子转移是反应的关 键一步.
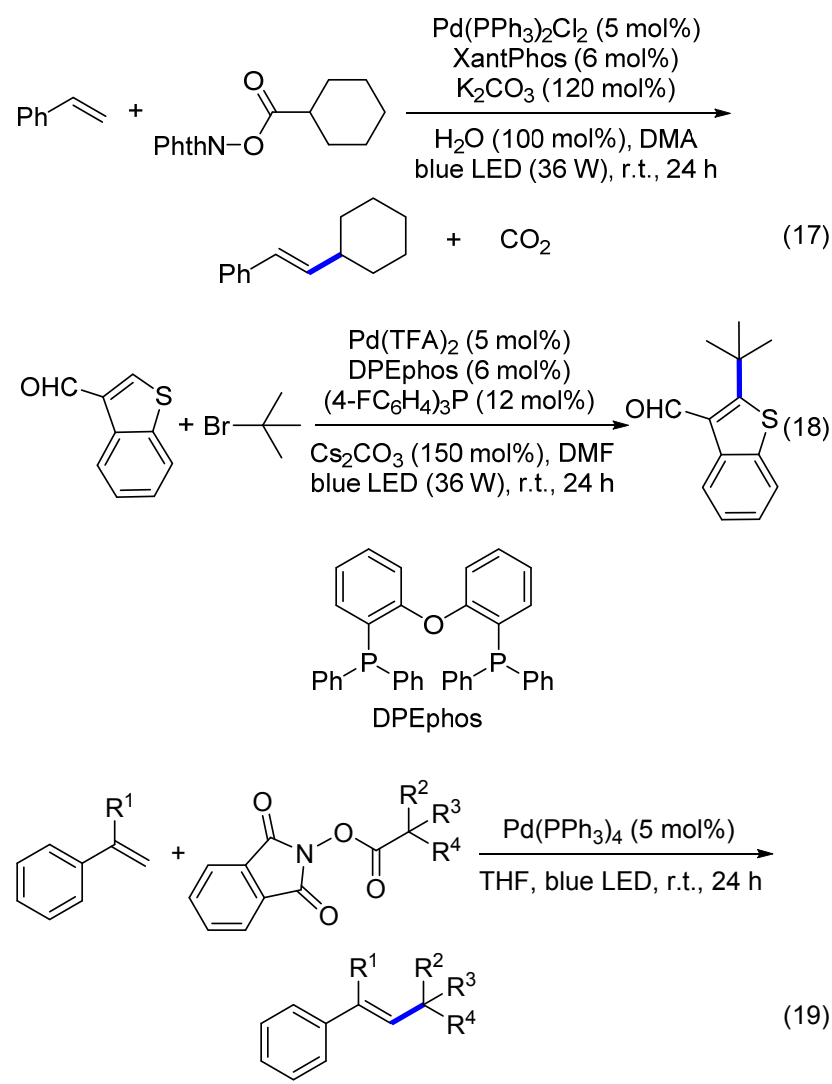

紧接着, Zhou 课题组 ${ }^{[39]}$ 报道了可见光促进钯催化 碘代烷烃和缺电子芳香烃的交叉偶联反应(Eq. 20). 反 应收率中等以上，具有较高的对位选择性，适用于缺电 子基团取代的䒺以及苯类化合物. 可以与 Friedel-Crafts 烷基化反应互补.

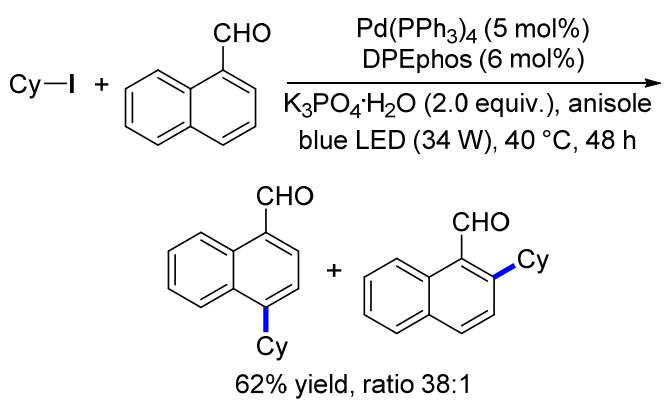

随后, Alcázar 课题组 ${ }^{[40]}$ 利用钯-锌复合物可以吸收 可见光特点, 实现了可见光直接促进的钯催化 Negishi 偶联反应(Scheme 9). 机理实验表明该反应的关键在于 原位生成的 $\mathrm{Pd}^{0}-\mathrm{Zn}$ 复合物吸收可以 $430 \mathrm{~nm}$ 波长的光, 从而加速该反应的氧化加成步骤.

2019 年, Rueping 和 Cavallo 等 ${ }^{[41]}$ 发展了在可见光照 射下钯催化 $\alpha, \beta$-不饱和羧酸与溴代烷烃的脱羧偶联反应 (Eq. 21). 该反应具有非常高的 $E / Z$ 立体选择性, 收率中 


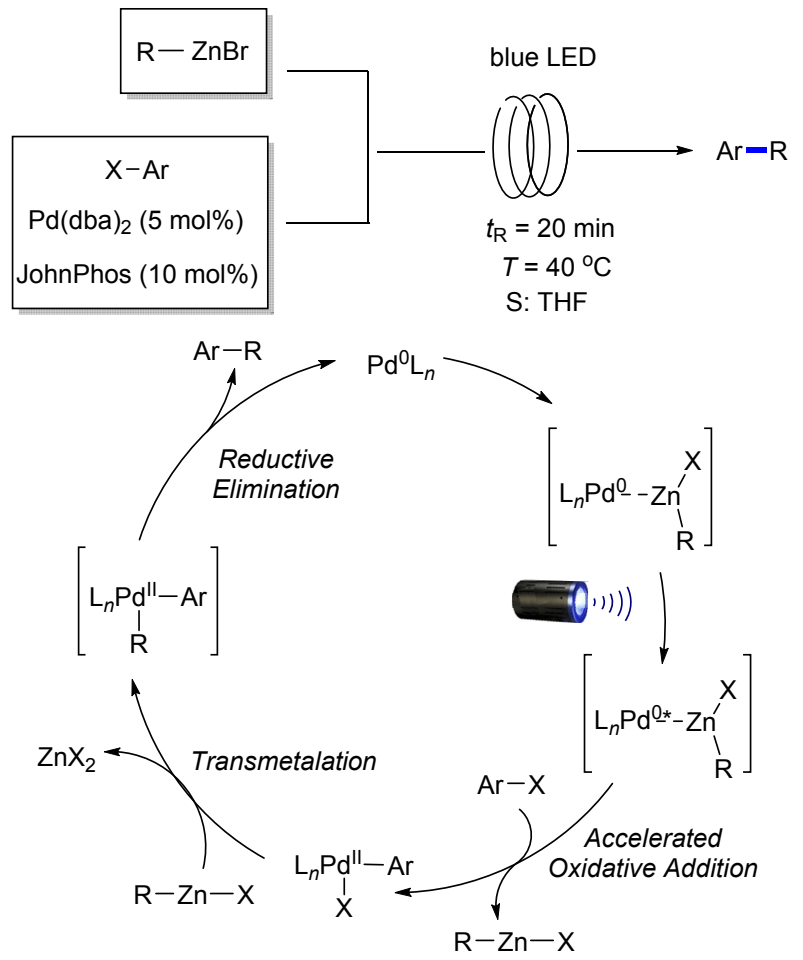

图式 9 可见光直接促进的钯催化锌格氏试剂和芳基卤代物 交叉偶联反应

Scheme 9 Palladium-catalyzed cross-coupling reaction of zinc Grignard reagent with aryl halides directly promoted by visible light

等至优秀, 适用于各级溴代烷烃. 机理研究表明该反应 能实现有效转化的关键在于激发态的钯复合物可以通 过单电子转移与卤代烷烃进行氧化加成.

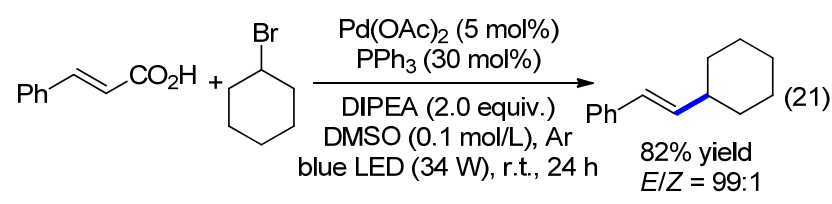

\section{6 可见光直接促进的铑催化交叉偶联反应}

用可见光直接促进铑催化的交叉偶联反应也是开 发反应类型、扩展反应新机制的有效方法. 最近, Basle 课题组 ${ }^{[42]}$ 报道了可见光直接促进的铑催化芳香化合物 $\mathrm{C}-\mathrm{H}$ 键与喼试剂偶联反应(Eq. 22). 该反应以高度的区 域选择性生成一系列芳香烃邻位嗍取代的偶联产物, 收 率中等至优秀. 研究表明可见光可以促进芳烃底物邻位 碳氢键与 $\mathrm{Rh}$ 催化剂的氧化加成得到 27 , 随后与硼试剂 反应，经还原消除得到偶联产物.

\section{7 可见光直接促进的钉催化交叉偶联反应}

钉化合物作为光催敏剂极大促进了光化学的发 展 $^{[4]}$. 最近, Greaney 课题组 ${ }^{[43]}$ 首次报道了可见光促进钌
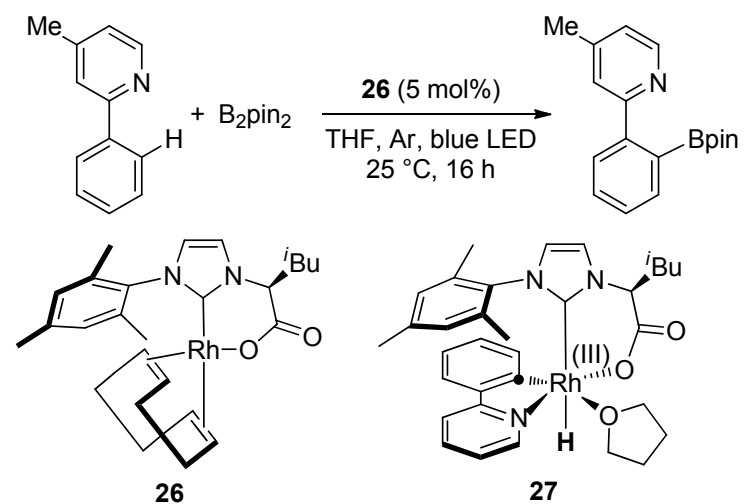

催化芳香化合物 $\mathrm{C}-\mathrm{H}$ 键与甾代烷烃的交叉偶联反应 (Eq. 23). 该反应收率中等至优秀, 适用于各级卤代烃且 具有高度的区域选择性, 当底物为二级和三级卤代烃 时, 选择性地得到间位取代的偶联产物, 为一级卤代烃 时反应则优先在邻位发生. 这与一级卤代烃具有较小的 空间位阻有关.

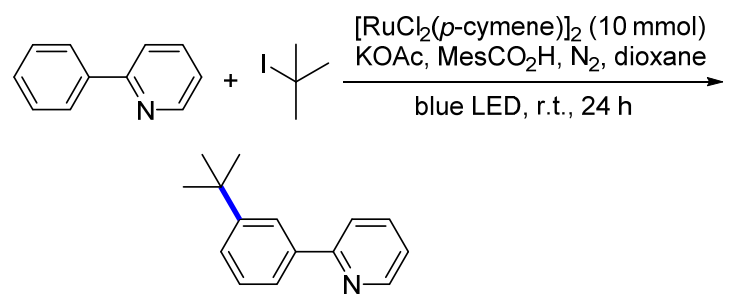

\section{8 可见光直接促进的金催化交叉偶联反应}

自 2000 年以来, 由于金具有良好的亲碳 $\pi$ 酸性，可 以活化不饱和碳碳键，金催化的亲核加成反应因此得到 了广泛的研究 ${ }^{[44]}$ ，当然在这些反应过程中金催化剂的 价态往往保持不变. 为了拓宽金催化的应用范围, 则需 要实现对金价态的调控. 然而与 $\mathrm{Pd}^{0} / \mathrm{Pd}^{\mathrm{II}}$ 催化循环相比, $\mathrm{Au} / \mathrm{Au}{ }^{\mathrm{III}}$ 具有较高的氧化还原电势, 需要外加强氧化剂 来推动反应的进行 ${ }^{[45]}$. 为了避免强氧化剂带来的不利 影响, Toste 和 glorius 课题组 ${ }^{[46]}$, 分别都报道了光氧化还 原催化和金催化结合的策略利用光敏剂对金进行价态 调控，发展了一批以芳基重氮盐或二芳基碘鎓盐作为芳 基自由基前体的交叉偶联反应.

在此基础上, 2017 年, Hashmi 课题组 ${ }^{[47]}$ 首次报道了 不外加光敏剂和氧化剂的金催化偶联反应(Scheme 10). 他们推测, $\mathrm{Au}^{\mathrm{I}}$ 催化剂可能与芳基重氮盐发生单电子转 移生成 $\mathrm{Au}^{\mathrm{II}}$ 复合物和芳基重氮自由基 $\mathbf{2 8}$, 两者随即结合 形成芳基重氮 $\mathrm{Au}^{\mathrm{III}}$ 复合物 29. 该复合物在可见光照射 下, 释放 $\mathrm{N}_{2}$ 转化为芳基 $\mathrm{Au}$ 吕复合物 30, 然后与芳基硼 酸或芳基硼酸频哪醇酯发生转金属化得到双芳基 $\mathrm{Au}{ }^{\mathrm{III}}$ 复合物 31, 最后快速发生还原消除生成联芳产物. 该反 应主要适用于缺电子的芳基嗍酸以及具有吸电子基团 
的芳基重氮盐底物.
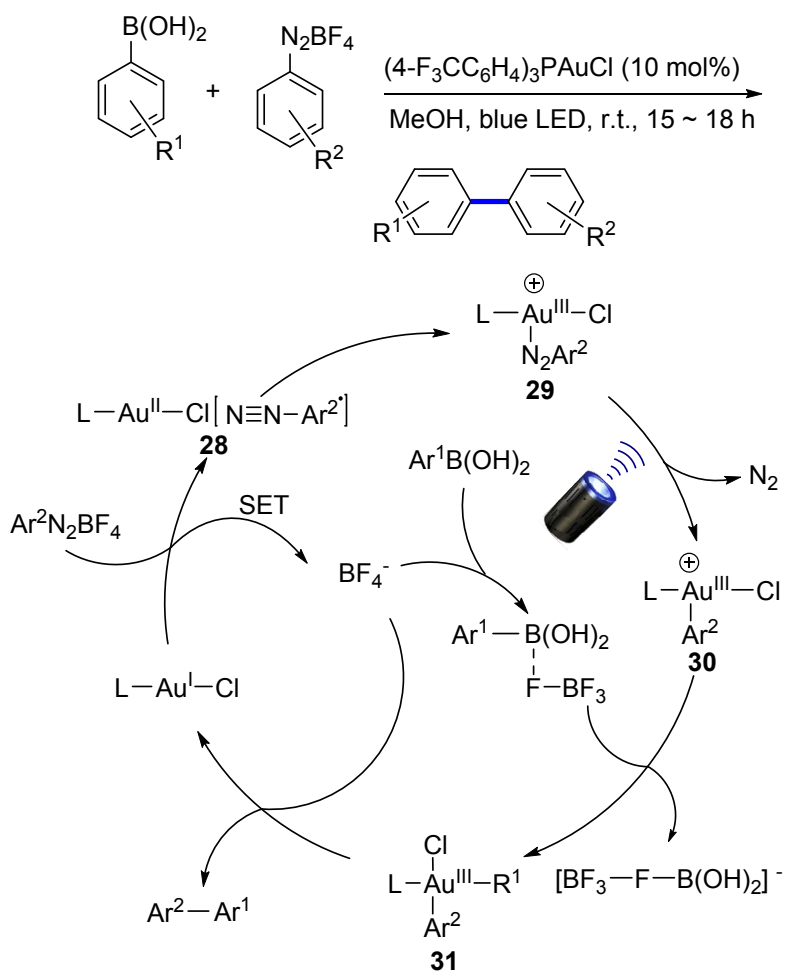

图式 10 可见光直接促进的金催化芳基重氮盐和芳基硼酸交 叉偶联反应

Scheme 10 Gold-catalyzed cross-coupling reaction of aryl diazonium salts and aryl boric acid directly promoted by visible light

次年, Hashmi 课题组 ${ }^{[48]}$ 在之前工作的基础上进一 步探索, 将反应底物从芳基硼酸、芳基硼酸频哪醇酯扩 展到了 MIDA 嗍酸酯 32、三氟硼酸盐 33. 另外发现三 甲氧基硅烷 34、双儿茶酚硅酸盐 35 也能与芳基重氮盐 发生偶联反应，可获得中等以上收率(Eq. 24).
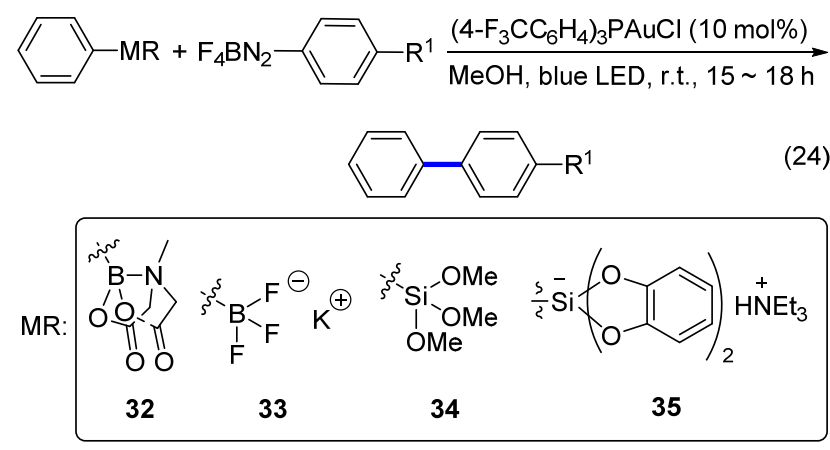

\section{9 可见光直接促进的非均相催化交叉偶联反应}

非均相催化剂与均相催化剂相比具有优势, 因为它 们很容易从反应溶液中分离出来并可在相同的反应条 件下循环使用. 近来, 使用非均相金属催化碳碳、碳杂 原子键偶联也是一种常用的策略 ${ }^{[49]}$.
2014 年, Zhu 课题组 ${ }^{[50]}$ 发现在可见光照射下 $\mathrm{Au}-\mathrm{Pd}$ 纳米材料可以高效催化 Suzuki 偶联反应. 机理实验表 明，该纳米材料具有多重性质，包括光吸收特性、与底 物强的相互作用以及过渡金属固有的催化活性，该材料 可以吸收可见光产生有效的高能电子，从而在纳米材料 表面促进底物分子发生偶联反应. 当纳米材料中的 $\mathrm{Au}$ 和 $\mathrm{Pd}$ 电子数几乎相等时, 该反应达到优异的活性, 对多 种底物都有良好的反应性. 作者用密度函数理论(DFT) 模拟计算发现，当电子进入纳米表面的碘苯分子的空轨 道后, $\mathrm{C}-\mathrm{I}$ 键键长从 $0.214 \mathrm{~nm}$ 延长至 $0.300 \mathrm{~nm}$, 因此有 利于 $\mathrm{C}-\mathrm{I}$ 键的裂解, 从而产生瞬时苯基负离子自由基, 随后进行氧化加成和还原消除得到产物。同年，该课题 组 ${ }^{[51]}$ 用 $\mathrm{Au}-\mathrm{Pd}$ 纳米材料在可见光照射下进行了 Sonogashira、Stille、Hiyama、Ullmanm 和 Buchwald-Hartwig 等一系列偶联反应的研究. 作者也使用 $\mathrm{Au}$ 和 $\mathrm{Pd}$ 单 独作催化剂以及在黑暗条件下进行了对照实验. 作者发 现，可见光照射下 $\mathrm{Au}-\mathrm{Pd}$ 纳米材料能有效地催化该类反 应并且反应的转换频率(TOF)值有显著提高.

2015 年, Bhalla 课题组 ${ }^{[52]}$ 用并五苯醌衍生物作反应 器和稳定剂, 在水中快速高效地合成 $\mathrm{Ag} @ \mathrm{CuO}_{2}$ 纳米材 料. 该材料可以在可见光照射下有效地催化 SuzukiMiyaura 和 Suzuki 类型的偶联反应. 次年, 王晓军课题 组 ${ }^{[53]}$ 设计合成了金属一有机框架(MOF)材料 Uio-68Se, 该材料在可见光下能高效催化需氧的交叉脱氢偶联反 应. 李朝晖课题组 ${ }^{[54]}$ 结合双溶剂法和光还原法, 将小于 $1.2 \mathrm{~nm}$ 的活性 Pd 纳米团簇包裹在 $\mathrm{NH}_{2}-\mathrm{Uio} 66(\mathrm{Zr})$ 的笼内, 制备了纳米材料 $\left[\mathrm{Pd} @ \mathrm{NH}_{2}-\mathrm{Uio}-66(\mathrm{Zr})\right]$, 由于该材料存 在大量配位不饱和活性的 $\mathrm{Pd}$ 催化位点, 以及光激发态 下 $\mathrm{NH}_{2}$-Uio 的有效电子转移, 在可见光照射下对 Suzuki 反应表现出比较好的活性.

2017 年, Kim 课题组 ${ }^{[55]}$ 用 Pd 纳米和 $2 \mathrm{H}-\mathrm{WS}_{2}$ 结合生 成 $2 \mathrm{H}-\mathrm{WS}_{2} / \mathrm{Pd}$ 纳米材料. 该材料在可见光照射下高效催 化 Suzuki 偶联反应. 该反应的 TOF 值高达 1244/h. 而且 该材料的催化活性在极性质子溶剂中可得到极大增强. 同年, Lim 课题组 ${ }^{[56]}$ 发现钯纳米粒子修饰的 $\mathrm{MoS}_{2}$ 纳米 片可作为高效的催化剂, 催化可见光引发的 SuzukiMiyaura 偶联反应. 在可见光照射下联苯产物的周转频 率大于 $1600 / \mathrm{h}$. 机理研究表明, 该材料的高催化活性源 自光照条件下 $\mathrm{MoS}_{2}$ 材料的有效电子-空穴对的生成, 而 不是纯粹的热效应.

2018 年, 该课题组 ${ }^{[57]}$ 又报道了可见光促进的钯-金 纳米胶体界面控制的 Suzuki-Miyaura 偶联反应. 作者发 现存在于纳米粒子与活性催化剂之间的石墨烯界面层 可以加速电子转移过程从而增强 $\mathrm{Pd}$ 纳米点的光催化效 率. Rezaeifard 课题组 ${ }^{[58]}$ 报道纳米材料 $\mathrm{TiO}_{2}-\mathrm{AA}-\mathrm{Co}$ 在可 
见光照射下可以催化醛与 $N$-羟基酰亚胺的脱氢交叉偶 联反应. 该反应以中等收率得到活性酯化合物. 郭成课 题组 ${ }^{[59]}$ 使用 $\mathrm{Pd} / \mathrm{CeO}_{2}$ 纳米材料作催化剂, 在可见光条件 下实现了不对称杂双芳烃化合物的合成. Studer 课题 组 ${ }^{\left[{ }^{[00]}\right.}$ 用甲硅烷基酮与二甲基甲酰胺中的 $\operatorname{Pd}(\mathrm{OAc})_{2}$ 制备 钯纳米粒子. 原位形成的 PdNPs 用聚乙烯吡咯烷酮进一 步稳定, 然后作为催化剂在可见光条件下高效催化芳基 嗍酸与芳基碘化物的 Suzuki-Miyaura 偶联, 以优异的收 率获得联苯产物. Yoshida 课题组 ${ }^{[61]}$ 在可见光条件下用 $\mathrm{Pd}$ 和 $\mathrm{TiO}_{2}$ 催化苯和环已烷的交叉偶联反应. 可见光激 发了 $\mathrm{TiO}_{2}$ 和苯的复合物, 生成的苯自由基阳离子与环 己烷发生质子转移生成环已基自由基, 随后该自由基与 苯环加成, 得到交叉偶联产物。

最近, 郎建平课题组 ${ }^{[62]}$ 通过钯纳米粒子与纳米多 孔聚咔唑 $(\mathrm{CNP})$ 结合得到杂化材料 $\mathrm{Pd} / \mathrm{CNP}$, 该材料可以 在蓝色 LED 照射下高效催化芳基氯与芳基硼酸的 Suzuki-Miyaura 反应. 该反应表现出良好的官能团耐受 性, 并且该催化剂可以循环再生且不会显著降低其催化 活性. 作者认为 $\mathrm{CNP}$ 不仅向 $\mathrm{Pd}$ 纳米颗粒提供光生电子, 还拥有用于活化芳基嗍酸的空穴.

\section{0 总结与展望}

本文总结了自 2011 年以来在不外加光敏剂的情况 下可见光直接促进的过渡金属催化交叉偶联反应的研 究进展, 也提出了部分采用紫外光激发的反应以及非均 相金属催化交叉偶联, 文中反应主要涉及 SuzukiMiyaura, Heck, Sonogashira, Stille, Kumada, Negishi, Ullmann 和 Hiyama 等人名反应. 这些可见光直接促进的 过渡金属催化偶联反应具有多种优势, 金属在反应中充 当了光敏剂和偶联催化剂双重作用. 此外, 廉价金属的 使用, 不仅开发了一系列新的反应策略, 而且大大降低 了反应成本, 有利于工业上的推广. 然而, 这种催化领 域目前也受到一些限制, 例如由于配体可调性差, 开发 不对称反应的难度很大. 该领域的未来发展方向是手性 配体的开发, 以及廉价金属(如 $\mathrm{Cu}, \mathrm{Fe}, \mathrm{Co}$ 和 $\mathrm{Ni}$ ) 催化体 系的进一步拓展.

\section{References}

[1] (a) Yi, H.; Zhang, G.; Wang, H. M.; Huang, Z. Y.; Wang, J.; Singh, A. K.; Lei, A. Chem. Rev. 2017, 117, 9016.

(b) Campeau, L.-C.; Hazari, N. Organometallics 2019, $38,3$.

(c) Korch, K. M.; Watson, D. A. Chem. Rev. 2019, 119, 8192

[2] (a) Suzuki, A. Angew. Chem., Int. Ed. 2011, 50, 6723.

(b) Negishi, E.-I. Angew. Chem., Int. Ed. 2011, 50, 6738.

(c) Johansson Seechurn, C. C. C.; Kitching, M. O.; Colacot, T. J.; Snieckus, V. Angew. Chem., Int. Ed. 2012, 51, 5062.

[3] (a) Narayanam, J. M. R.; Stephenson, C. R. J. Chem. Soc. Rev. 2011, 40,102

(b) Xuan, J.; Xiao, W. J. Angew. Chem., Int. Ed. 2012, 51, 6828. (c) Romero, N. A.; Nicewicz, D. A. Chem. Rev. 2016, 116, 10075. (d) Wei, Y.; Zhou, Q.-Q.; Tan, F.; Lu, L.-Q.; Xiao, W.-J. Synthesis 2019, 51, 3021.

(e) Ye, H.; Xiao, C.; Lu, L. Q. Chin. J. Org. Chem. 2018, 38, 1897 (in Chinese).

(叶辉，肖聪，陆良秋，有机化学, 2018, 38, 1897.)

(f) Ruan, L. H.; Chen, C. X.; Zhang, X. X.; Sun, J. Chin. J. Org. Chem. 2018, 38, 3155 (in Chinese).

(阮利衡, 陈春欣, 张晓欣, 孙京, 有机化学, 2018, 38, 3155.)

(g) Zhang, H.; Yu. S. Y. Chin. J. Org. Chem. 2019, 39, 95 (in Chinese).

(张昊，俞寿云，有机化学， 2019, 39, 95.)

(h)Xu, W. X.; Dai, X. Q.; Xu, H. J.; Weng, J. Q. Chin. J. Org. Chem. 2018, 38, 2807 (in Chinese).

(徐雯秀, 戴小强, 徐涵靖, 翁建全, 有机化学, 2018, 38, 2807.)

[4] (a) Skubi, K. L.; Blum, T. R.; Yoon, T. P. Chem. Rev. 2016, 116, 10035 .

(b) Twilton, J.; Le, C.; Zhang, P.; Shaw, M. H.; Evans, R. W.; MacMillan, D. W. C. Nat. Rev. Chem. 2017, 1, 0052.

[5] Sagadevan, A.; Hwang, K. C. Adv. Synth. Catal. 2012, 354, 3421.

[6] Sagadevan, A.; Lyu, P.-C.; Hwang, K. C. Green Chem. 2016, 18, 4526.

[7] Charpe, V. P.; Hande, A. A.; Sagadevan, A.; Hwang, K. C. Green Chem. 2018, 20, 4859.

[8] Creutz, S. E.; Lotito, K. J.; Fu, G. C.; Peters, J. C. Science 2012, $338,647$.

[9] Hossain, A.; Bhattacharyya, A.; Reiser, O. Science 2019, 364, 450.

[10] Kainz, Q. M.; Matier, C. D.; Bartoszewicz, A.; Zultanski, S. L.; Peters, J. C.; Fu, G. C. Science 2016, 351, 681.

[11] Zhao, W.; Wurz, R. P.; Peters, J. C.; Fu, G. C. J. Am. Chem. Soc. 2017, 139, 12153.

[12] Matier, C. D.; Schwaben, J.; Peters, J. C.; Fu, G. C. J. Am. Chem. Soc. 2017, 139, 17707

[13] Ahn, J. M.; Peters, J. C.; Fu, G. C. J. Am. Chem. Soc. 2017, 139, 18101.

[14] He, J.; Chen, C.; Fu, G. C.; Peters, J. C. ACS Catal. 2018, 8, 11741.

[15] Hazra, A.; Lee, M. T.; Chiu, J. F.; Lalic, G. Angew. Chem., Int. Ed. 2018, 57, 5492.

[16] Yu, X.-Y.; Zhao, Q.-Q.; Chen, J.; Chen, J.-R.; Xiao, W.-J. Angew. Chem., Int. Ed. 2018, 57, 15505 .

[17] Yang, L.; Zhang, J.-Y.; Duan, X.-H.; Gao, P.; Jiao, J.; Guo, L.-N. J. Org. Chem. 2019, 84, 8615.

[18] Xiong, Y.; Ma, X. D.; Zhang, G. Z. Org. Lett. 2019, 21, 1699.

[19] Toth, B. L.; Tischler, O.; Novak, Z. Tetrahedron Lett. 2016, 57, 4505.

[20] Abdiaj, I.; Fontana, A.; Gomez, M. V.; de la Hoz, A.; Alcázar, J. Angew. Chem., Int. Ed. 2018, 57, 8473.

[21] Abdiaj, I.; Horn, C. R.; Alcázar, J. J. Org. Chem. 2019, 84, 4748.

[22] Gandolfo, E.; Tang, X. J.; Raha Roy, S.; Melchiorre, P. Angew. Chem., Int. Ed. 2019, 58, 16854.

[23] Cahiez, G.; Moyeux, A. Chem. Rev. 2010, 110, 1435.

[24] Weiss, M. E.; Kreis, L. M.; Lauber, A.; Carreira, E. M. Angew. Chem., Int. Ed. 2011, 50, 11125.

[25] Kreis, L. M.; Krautwald, S.; Pfeiffer, N.; Martin, R. E.; Carreira, E. M. Org. Lett. 2013, 15, 1634

[26] Song, J.-Y.; Zhou, X.; Song, H.; Liu, Y.; Zhao, H.-Y.; Sun, Z.-Z.; Chu, W.-Y. ChemCatChem 2018, 10, 758 .

[27] Ravetz, B. D.; Wang, J. Y.; Ruhl, K. E.; Rovis, T. ACS Catal. 2019, 9, 200.

[28] Bauer, I.; Knölker, H.-J. Chem. Rev. 2015, 115, 3170.

[29] Wei, X.-J.; Abdiaj, I.; Sambiagio, C.; Li, C. F.; Zysman-Colman, E.; Alcázar, J.; Noël, T. Angew. Chem., Int. Ed. 2019, 58, 13030.

[30] Biffis, A.; Centomo, P.; Del Zotto, A.; Zecca, M. Chem. Rev. 2018, $118,2249$.

[31] Roslin, S.; Odell, L. R. Chem. Commun. 2017, 53, 6895.

[32] Kurandina, D.; Parasram, M.; Gevorgyan, V. Angew. Chem., Int. Ed. 2017, 56, 14212 .

[33] Wang, G. Z.; Shang, R.; Cheng, W. M.; Fu, Y. J. Am. Chem. Soc. 
2017, 139, 18307

[34] Zhou, W.-J.; Cao, G.-M.; Shen, G.; Zhu, X.-Y.; Gui, Y.-Y.; Ye, J.-H.; Sun, L.; Liao, L.-L.; Li, J.; Yu, D.-G. Angew. Chem., Int. Ed. 2017, $56,15683$.

[35] Kurandina, D.; Rivas, M.; Radzhabov, M.; Gevorgyan, V. Org. Lett. 2018, 20, 357 .

[36] Wang, G.-Z.; Shang, R.; Fu, Y. Org. Lett. 2018, 20, 888.

[37] Wang, G.-Z.; Shang, R.; Fu, Y. Synthesis 2018, 50, 2908.

[38] Koy, M.; Sandfort, F.; Tlahuext-Aca, A.; Quach, L.; Daniliuc, C. G.; Glorius, F. Chem.-Eur. J. 2018, 24, 4552.

[39] Jiao, Z. W.; Lim, L. H.; Hirao, H.; Zhou, J. S. Angew. Chem., Int. Ed. 2018, 57, 6294.

[40] Abdiaj, I.; Huck, L.; Mateo, J. M.; de la Hoz, A.; Gomez, M. V.; Díaz-Ortiz, A.; Alcázar, J. Angew. Chem., Int. Ed. 2018, 57, 13231.

[41] Kancherla, R.; Muralirajan, K.; Maity, B.; Zhu, C.; Krach, P. E.; Cavallo, L.; Rueping, M. Angew. Chem., Int. Ed. 2019, 58, 3412.

[42] Thongpaen, J.; Manguin, R.; Dorcet, V.; Vives, T.; Duhayon, C.; Mauduit, M.; Basle, O. Angew. Chem., Int. Ed. 2019, 58, 15244.

[43] Sagadevan, A.; Greaney, M. F. Angew. Chem., Int. Ed. 2019, 58, 9826.

[44] (a) Pflaesterer, D.; Hashmi, A. S. K. Chem. Soc. Rev. 2016, 45, 1331.

(b) Xie, J.; Li, J.; Weingand, V.; Rudolph, M.; Hashmi, A. S. K. Chem.-Eur. J. 2016, 22, 12646.

(c) Xie, J.; Jin, H. M.; Hashmi, A. S. K. Chem. Soc. Rev. 2017, 46, 5193 .

(d) Harper, M. J.; Arthur, C. J.; Crosby, J.; Emmett, E. J.; Falconer, R. L.; Fensham-Smith, A. J.; Gates, P. J.; Leman, T.; McGrady, J. E.; Bower, J. F.; Russell. C. A. J. Am. Chem. Soc. 2018, 140, 4440.

[45] (a) Huang, L.; Rominger, F.; Rudolph, M.; Hashmi, A. S. K. Chem. Commun. 2016, 52, 6435.

(b) Zhang, G. Z.; Peng, Y.; Cui, L.; Zhang, L. M. Angew. Chem., Int. Ed. 2009, 48, 3112.
[46] (a) Kim, S.; Rojas-Martin, J.; Toste, F. D. Chem. Sci. 2016, 7, 85. (b) Tlahuext-Aca, A.; Hopkinson, M. N.; Sahoo, B.; Glorius, F. Chem. Sci. 2016, 7, 89 .

[47] Witzel, S.; Xie, J.; Rudolph, M.; Hashmi, A. S. K. Adv. Synth. Catal. 2017, 359, 1522.

[48] Witzel, S.; Sekine, K.; Rudolph, M.; Hashmi, A. S. K. Chem. Commun. 2018, 54, 13802

[49] Gu, Q.; Jia, Q. H.; Long, J. L.; Gao, Z. W. ChemCatChem 2019, 11, 669.

[50] Xiao, Q.; Sarina, S.; Jaatinen, E.; Jia, J. F.; Arnold, D. P.; Liu, H. W; Zhu, H. Y. Green Chem. 2014, 16, 4272.

[51] Xiao, Q.; Sarina, S.; Bo, A.; Jia, J. F.; Arnold, D. P.; Huang, Y. M.; Wu, H. H.; Zhu, H. Y. ACS Catal. 2014, 4, 1725.

[52] Sharma, K.; Kumar, M.; Bhalla, V. Chem. Commun. 2015, 51, 12529.

[53] Zhang, W.-Q.; Li, Q.-Y.; Zhang, Q.; Lu, Y.-.; Lu, H.; Wang, W.-G.; Zhao, X.-S.; Wang, X.-J. Inorg. Chem. 2016, 55, 1005.

[54] Sun, D. R.; Li, Z. H. J. Phys. Chem. C 2016, 120, 19744.

[55] Raza, F.; Yim, D. B.; Park, J. H.; Kim, H. I.; Jeon, S. J.; Kim, J. H. J. Am. Chem. Soc. 2017, 139, 14767.

[56] Shin, H. H.; Kang, E.; Park, H.; Han, T.; Lee, C. H.; Lim, D. K. J. Mater. Chem. A 2017, 5, 24965.

[57] Kang, E.; Shin, H. H; Lim, D.-K. Catalysts 2018, 8, 463.

[58] Feizpour, F.; Jafarpour, M.; Rezaeifard, A. New J. Chem. 2018, 42, 807.

[59] Ge, Y. Q.; Diao, P. H.; Xu, C.; Zhang, N. N.; Guo, C. Chin. Chem. Lett. 2018, 29, 903.

[60] Masing, F.; Nusse, H.; Klingauf, J.; Studer, A. Org. Lett. 2018, 20 , 752.

[61] Yamamoto, A.; Ohara, T.; Yoshida, H. Catal. Sci. Technol. 2018, 8, 2046.

[62] Guo, B.; Li, H.-X.; Zha, C.-H.; Young, D. J.; Li, H.-Y.; Lang, J.-P. ChemSusChem 2019, 12, 1421.

(Cheng, F.) 